\begin{tabular}{cc}
\hline V 62 (1) & 2019 \\
KHIMESTIYA VYSSHIKH UCHEBNYKH ZAVEDENII & \\
RUSSIAN JOURNAL OF CHEMISTRY AND CHEMICAL TECHNOLOGY & DOI: $10.6060 /$ ivkkt.20196201.5763 \\
УДК: $547.466: 543.2$ \\
МЕЖФАЗНОЕ РАСПРЕДЕЛЕНИЕ НЕКОТОРЫХ АМИНОКИСЛОТ В \\
ЭКСТРАКЦИОННЫХ СИСТЕМАХ НА ОСНОВЕ СОПОЛИМЕРОВ N-ВИНИЛФРМАМИДА
\end{tabular}

ИЗВЕСТИЯ ВЫСШИХ УЧЕБНЫХ ЗАВЕДЕНИЙ.

Надежда Яковлевна Мокшина*

Кафедра физики и химии, ВУНЦ ВВС «Военно-воздушная академия им. проф. Н.Е. Жуковского и Ю.А. Гагарина», ул. Старых Большевиков, 54а, Воронеж, Российская Федерация, 394063

E-mail: moksnad@mail.ru

Оксана Анатольевна Пахомова

Кафедра химии и биологии, Елецкий государственный университет им. И.А. Бунина, ул. Коммунаров, 28, Елец, Российская Федерация, 399770

E-mail: pakhomchik@mail.ru

Геннадий Валентинович Шаталов

Кафедра химии высокомолекулярных соединений и коллоидов, Воронежский государственный университет, Университетская пл., 1, Воронеж, Российская Федерация, 394018

E-mail: vms159@mail.ru

Ирина Ивановна Косинова

Кафедра экологической геологии, Воронежский государственный университет, Университетская пл., 1, Воронеж, Российская Федерация, 394018

E-mail: kosinova777@yandex.ru

\begin{abstract}
Изучены экстракционные характеристики аминокислот и моноамидов кислот при использовании сополимеров N-винилформамида с 1-винил- и 1-метакрилоил-3,5диметилпиразолом в качестве экстрагентов. Синтез водорастворимых сополимеров осущцествлен радикальной сополимеризацией в диоксане при термоинициировании с помощью динитрила азобисизомасляной кислоты. Рассчитаны коэффициенты распределения и степень извлечения аналитов при однократной экстракции в присутствии высаливателя. Для определения представителей аминокислот применяли метод капиллярного электрофореза. Предложены наиболее эффективные экстракционные системы для извлечения аминокислот и моноамидов кислот: характеристическая вязкость полимеров, концентрация раствора полимера и аналита, соотношение объемов фаз, соотношение мольных долей $N$-винилформамида с 1-винил- и 1-метакрилоил-3,5-диметилпиразолом. Представлены результаты наиболее эффективного межфазного распределения лизина между водно-солевым раствором и экстрагентом, в качестве которого предложен сополимер

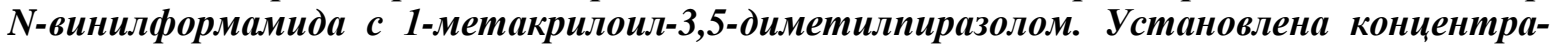
ция сополимера и соотношение объемов равновесных фаз, при которых достигаются максимальные степени извлечения лизина. Сополимер $N$-винилформамида $c$ 1-винил-3,5-диметилпиразолом применен для одновременного извлечения цистина, аспарагина и глутамина. Установленные экстракционные характеристики позволили провести успешное раздельное определение аминокислоты цистина и моноамидов (аспарагина и глутамина) при совместном присутствии в водном растворе. При выборе условий раздельного электрофоретического определения аминокислот найдены оптимальный состав буферного раствора, тип и концентрация мицеллообразователя. Установлена зависимость структуры аналитов с их межфазным распределением, а такље выявлена
\end{abstract}


комплексообразующая способность сополимеров $N$-винилформамида с 1-винил- и 1-метакрилоил-3,5-диметилпиразолом по отношению к представителям аминокислот. Используемые экстракционные системы на основе сополимеров $N$-винилформамида отличаются экологической и экономической целесообразностью, хорочими метрологическими показателями.

Ключевые слова: сополимеры винилформамида, экстракция, аминокислоты, коэффициенты распределения, степень извлечения, электрофоретическое определение

\title{
INTERPHASE DISTRIBUTION OF SOME AMINO ACIDS IN EXTRACTION SYSTEMS BASED ON N-VINYLFORMAMIDE COPOLYMERS
}

\author{
N.Ya. Mokshina, O.A. Pakhomova, G.V. Shatalov, I.I. Kosinova \\ Nadezhda Ya. Mokshina* \\ Department of chemistry and physic, Military Educational and Scientific Center of the Air Force «N.E. Zhukovsky \\ and Yu.A. Gagarin Air Force Academy», St. Bol'shevikov str., 54 a, Voronezh, 394064, Russia \\ E-mail: moksnad@mail.ru* \\ Oksana A. Pakhomova \\ Department of chemistry and biology, I.A. Bunin Yelets State University, Kommunarov st., 28, Yelets, 399770, \\ Russia \\ E-mail: pakhomchik@mail.ru \\ Gennadiy V. Shatalov \\ Department of chemistry of macromolecules compounds and colloids, Voronezh State University, Universitetskaya sq., \\ 1, Voronezh, 394018, Russia \\ E-mail:vms159@mail.ru \\ Irina I. Kosinova \\ Department of ecological geology, Voronezh State University, Universitetskaya sq., 1, Voronezh, 394018, Russia \\ E-mail: kosinova777@yandex.ru
}

The extraction characteristics of amino acids and mono-amides of acids were studied using copolymers of $\mathrm{N}$-vinylformamide with 1-vinyl- and 1-methacryloyl-3,5-dimethylpyrazole as extractants. Synthesis of water-soluble copolymers was carried out by radical copolymerization in dioxane with thermoinitiation with dinitro-azobisisomoic acid. The distribution coefficients and the degree of extraction of analytes for a single extraction in the presence of a salting out agent are calculated. To determine the representatives of amino acids, the method of capillary electrophoresis was used. The most effective extraction systems for the extraction of amino acids and monoamides of acids are proposed: the intrinsic viscosity of polymers, the concentration of polymer and analyte solution, the ratio of phase volumes, the ratio of the mole fractions of $\mathrm{N}$-vinylformamide to 1-vinyl and 1-methacryloyl-3,5-dimethylpyrazole. The results of the most effective interfacial distribution of lysine between a water-salt solution and an extractant are presented, which is a copolymer of $N$-vinylformamide with 1-methacryloyl-3,5-dimethylpyrazole. The concentration of the copolymer and the ratio of the volumes of equilibrium phases at which the maximum degree of lysine extraction is reached are established. A copolymer of $N$-vinylformamide with 1-vinyl-3,5-dimethylpyrazole is used for simultaneous extraction of cystine, asparagine and glutamine. The established extraction characteristics allowed a successful separate determination of the amino acid cystine and monoamides (asparagine and glutamine) in a joint presence in an aqueous solution. When choosing the conditions for separate electrophoretic determination of amino acids, the optimal composition of the buffer solution, the type and concentration of the micelle was found. The dependence of the structure of the analytes on their interphase distribution was established, and the complexing power of the copolymers of $N$-vinylformamide with 1-vinyland 1-methacryloyl-3,5-dimethylpyrazole was revealed with respect to the representatives of amino acids. The extraction systems used on the basis of $N$-vinylformamide copolymers are distinguished by ecological and economic expediency, good metrological indices. 
Key words: copolymers of a vinilformamid, extraction, amino acids, distribution coefficients, extraction degree, electrophoretic determination

\section{Для цитирования:}

Мокшина Н.Я., Пахомова О.А., Шаталов Г.В., Косинова И.И. Межфазное распределение некоторых аминокислот в экстракционных системах на основе сополимеров N-винилформамида. Изв. вузов. Химия и хим. технология. 2019. Т. 62. Вып. 1. С. $4-10$

For citation:

Mokshina N. Ya., Pakhomova O. A., Shatalov G. V., Kosinova I.I. Interphase distribution of some amino acids in extraction systems based on N-vinylformamide copolymers. Izv. Vyssh. Uchebn. Zaved. Khim. Khim. Tekhnol. 2019. V. 62. N 1. P. 4-10

\section{ВВЕДЕНИЕ}

В условиях современных объемов производств пищевой, медицинской, сельскохозяйственной индустрий получение аминокислот является одной из наиболее масштабных отраслей. Это связано с их широким применением в биохимии, получении пищевых добавок, медицинских препаратов, кормов и витаминных комплексов. Наибольшие объемы получения характерны для лизина, глутамина, аспарагина и цистина. Синтез таких продуктов представляет собой актуальную биотехнологическую задачу, поскольку аминокислотный дефицит способствует развитию дисфункции обменных процессов в организме человека. В связи с этим недостаток лизина, глутамина, аспарагина и цистина необходимо восполнять дополнительным включением экзогенных аминокислот в рацион питания $[1,2]$.

Ежегодно расширяется перечень лекарственных форм, содержащих аминокислоты в свободной и связанной форме [3, 4]. Направленное эффективное воздействие препаратов на основе смесей аминокислот и их замещенных основано на анаболическом и антиоксидантом эффекте, стимуляции энергообеспечения и регенерации [5]. Поступление в организм свободных форм аминокислот не сопровождается повышенными энергетическими затратами на расщепление при всасывании, в отличие от белка.

Физико-химические свойства, удовлетворение требованиям экологичности и экономической целесообразности делают экстракционные системы на основе водорастворимых гомо- и сополимеров, а также поверхностно-активных веществ весьма привлекательными для решения практических задач, связанных с извлечением и количественным определением биологически активных веществ [6-9].

Известно применение водорастворимых полимеров, в частности, на основе винилформамида, для извлечения и определения соединений разных классов [10, 11]. В таких системах достигаются высокие экстракционные характеристики распределяемых веществ, что позволяет предположить эффективность полимерных систем на основе $\mathrm{N}$-винилформамида в качестве экстрагентов аминокислот и их производных.

Цель работы - установление экстракционных характеристик межфазного распределения аминокислот и моноамидов кислот в водно-солевых системах на основе водорастворимых сополимеров $\mathrm{N}$-винилформамида с 1-винил- и 1-метакрилоил-3,5-диметилпиразолом.

Для достижения поставленной цели в работе осуществлен синтез сополимеров $\mathrm{N}$-винилформамида с 1-винил- и 1-метакрилоил-3,5-диметилпиразолом, проявляющих высокую комплексообразующую способность. Изучено межфазное распределение аминокислот в системах на основе полученных сополимеров; предложена схема взаимодействия сополимеров с извлекаемыми веществами; установлены наиболее эффективные условия для практически полного извлечения аминокислот из водных сред. Для определения аминокислот после их экстракции обычно применяют хроматографические или спектрофотометрические методы анализа [12]. Одним из эффективных методов разделения аминокислот может быть электрофорез на различных носителях (целлюлозе, гелях, порошках и др.), поэтому нами осуществлено электрофоретическое определение аналитов [13-15].

\section{МЕТОДИКА ЭКСПЕРИМЕНТА}

В табл. 1 представлены структуры объектов исследования. Лизин относится к диаминомонокарбоновым аминокислотам, имеющим в водном растворе щелочную реакцию за счет наличия двух аминных групп.

Аспарагин и глутамин относятся к моноамидам аспарагиновой и глутаминовой аминокислот, которые имеют одну аминную и одну карбоксильную группы, и в водном растворе дают кислую реакцию. 
Цистин - некодируемая аминокислота, представляющая собой продукт окислительной димеризации цистеина, в ходе которой две тиольные группы цистеина образуют дисульфидную связь цистина. Цистин содержит две амино- и две карбоксильных группы и относится к двухосновным диаминокислотам.

Таблица 1

Структуры аминокислот и моноамидов кислот

Table 1. Structures of amino acids and monoamides of acids

\begin{tabular}{|c|c|}
\hline $\begin{array}{c}\text { Объект } \\
\text { исследо- } \\
\text { вания }\end{array}$ & Структурная формула \\
\hline Лизин & $\mathrm{NH}_{2}-\mathrm{CH}_{2}-\mathrm{CH}_{2}-\mathrm{CH}_{2}-\mathrm{CH}_{2}-\mathrm{CH}\left(\mathrm{NH}_{2}\right)-\mathrm{COOH}$ \\
\hline Аспарагин & $\mathrm{NH}_{2}-\mathrm{CO}-\mathrm{CH}_{2}-\mathrm{CH}\left(\mathrm{NH}_{2}\right)-\mathrm{COOH}$ \\
\hline Глутамин & $\mathrm{NH}_{2}-\mathrm{CO}-\mathrm{CH}_{2}-\mathrm{CH}_{2}-\mathrm{CH}\left(\mathrm{NH}_{2}\right)-\mathrm{COOH}$ \\
\hline Цистин & $\mathrm{S}_{2}\left(\mathrm{CH}_{2}-\mathrm{CH}\left(\mathrm{NH}_{2}\right)-\mathrm{COOH}\right)_{2}$ \\
\hline
\end{tabular}

Для синтеза сополимеров применяли свежеперегнанный $\mathrm{N}$-винилформамид (ВФ) фирмы «Aldrich» с $T_{\text {кип }}=78-79{ }^{\circ} \mathrm{C} / 10$ мм рт. ст. и $n^{20}{ }_{D}=1,5330$. Сополимеры ВФ с 1 -винил (ВДМП)- и 1-метакрилоил-3,5-диметил-пиразолом (МДМП), которым отвечают соответственно $T_{\text {кип }}=80-82{ }^{\circ} \mathrm{C} / 10$ мм рт. ст. и и $n^{20}{ }_{D}=1,5150$, и $T_{\text {кии }}=82-84^{\circ} \mathrm{C} / 20$ мм рт. ст. и $n^{20}{ }_{D}=1,5011$, синтезировали в соответствии с работой [16]:<smiles>C=CNC=O</smiles><smiles>C=Cn1nc(C)cc1C</smiles>

$\mathrm{B} \Phi$<smiles>C=C(C)C(=O)n1nc(C)cc1C</smiles>

МДМП
Радикальную сополимеризацию проводили в диоксане классификации ЧДА с концентрацией сомономеров $\left[\mathrm{M}_{1}\right]+\left[\mathrm{M}_{2}\right]=1$ моль/л и содержанием инициатора динитрила азо-бис-изомаслянной кислоты $1,0 \cdot 10^{-2}$ моль/л при $70 \pm 2{ }^{\circ} \mathrm{C}$ в течение 10 ч. Сополимеризацию проводили в условиях, исключающих наличие кислорода воздуха, используя аргон. Полученные сополимеры выделяли и сушили в вакууме при 55-60 ${ }^{\circ} \mathrm{C}$ согласно [16]. Водорастворимые сополимеры ВФ с ВДМП и МДМП отвечали соотношению звеньев в макроцепи соответственно 90:10 и величинам характеристической вязкости $\eta=0,40$ дл/г и $\eta=0,55$ дл/г (в 0,2 моль/дм ${ }^{3}$ растворе $\mathrm{NaCl}$ при $20^{\circ} \mathrm{C}$ ).
Известно, что для установления состава и структур образующихся комплексов и ассоциатов в разнохарактерных системах, включающих биологически активные вещества, успешно применяются методы УФ- и ИК-спектроскопии $[6,10,17]$. В настоящей работе для определения составов сополимеров применяли ИК-спектроскопию. ИК спектры регистрировали в диапазоне частот 4400$400 \mathrm{~cm}^{-1}$ на спектрофотометре Bruker Vertex $70 \mathrm{c}$ Фурье-преобразователем методом нарушенного полного внутреннего отражения. Состав сополимеров вычисляли из данных соотношения площадей полос поглощения, отвечающих валентным колебаниям $>\mathrm{C}=\mathrm{O}$ группы ВФ $\left(1643 \mathrm{~cm}^{-1}\right)$, и полосы поглощения $1550 \mathrm{~cm}^{-1}$, относящейся к пиразольному циклу ВДМП и МДМП [16].

Экстракцию аминокислот проводили по известной методике [18]. В качестве высаливателя применяли сульфат аммония, время достижения межфазного равновесия - 5-7 мин. С целью выбора оптимальных режимов экстракции эксперименты проводили при разных соотношениях водносолевой и органической фаз (r) и разных концентрациях полимеров. Рассчитывали коэффициенты распределения (D) и степень извлечения (R, \%) аналитов, результаты метрологически обрабатывали (при $\mathrm{n}=3, \mathrm{P}=0,95)$.

Содержание аминокислот в водной фазе после экстракции определяли электрофоретически, на приборе «Капель-105» при следующих условиях: ввод пробы при давлении 30 мбар в течение 5 c, напряжение +25 кB, температура $20^{\circ} \mathrm{C}$, время ввода пробы 7 мин, ведущий электролит смесь раствора додецилсульфата натрия и тетрабората натрия. Регистрировали электрофореграммы, проверяли правильность автоматической разметки пиков, с помощью программного обеспечения «Эльфоран» идентифицировали компоненты.

\section{РЕЗУЛЬТАТЫ И ИХ ОБСУЖДЕНИЕ}

Изучение межфазного распределения лизина в экстракционных системах на основе сополимеров ВФ-МДМП и ВФ-ВДМП при различных соотношениях равновесных водной и органической фаз и концентрациях полимера показало, что наибольшую эффективность проявляет система с содержанием водорастворимого сополимера ВФМДМП (табл. 2).

Анализируя данные табл. 2, можно сделать вывод, что для извлечения лизина наиболее эффективно соотношение водной фазы аминокислоты и органической фазы раствора полимера $r=10: 3$. При других соотношениях фаз лизин извлекается 
эффективно, но не количественно ( $\mathrm{R} \leq 96 \%)$. Кроме того, такое соотношение объемов фаз позволяет определять достаточно низкие концентрации лизина.

Таблица 2

Результаты межфазного распределения лизина в системе ВФ-МДМП

Table 2. Results of interphase distribution of lysine in the VF-MDMP system

\begin{tabular}{|c|c|c|}
\hline 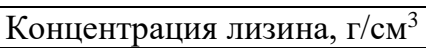 & $\mathrm{D}$ & $\mathrm{R}, \%$ \\
\hline \multicolumn{3}{|c|}{ 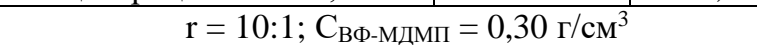 } \\
\hline 0,015 & $248 \pm 11$ & 96,0 \\
\hline 0,025 & $351 \pm 12$ & 97,2 \\
\hline 0,030 & $356 \pm 12$ & 97,3 \\
\hline 0,035 & $359 \pm 13$ & 97,3 \\
\hline \multicolumn{3}{|c|}{$\mathrm{r}=10: 2 ; \mathrm{C}_{\text {ВФ-МдмП }}=0,25 \Gamma / \mathrm{cm}^{3}$} \\
\hline 0,015 & $156 \pm 6$ & 96,9 \\
\hline 0,025 & $168 \pm 5$ & 97,1 \\
\hline 0,030 & $202 \pm 8$ & 97,6 \\
\hline 0,035 & $212 \pm 8$ & 97,7 \\
\hline \multicolumn{3}{|c|}{$\mathrm{r}=10: 3 ; \mathrm{C}_{\mathrm{B} \Phi-М д М \Pi}=0,20 \Gamma / \mathrm{cm}^{3}$} \\
\hline 0,015 & $264 \pm 12$ & 98,8 \\
\hline 0,025 & $288 \pm 12$ & 98,9 \\
\hline 0,030 & $316 \pm 14$ & 99,1 \\
\hline 0,035 & $303 \pm 13$ & 99,0 \\
\hline
\end{tabular}

При увеличении концентрации полимера в системе выше $0,03 \mathrm{r} / \mathrm{cm}^{3}$ не происходит существенного увеличения экстракционных характеристик лизина. Это связано с тем, что в водном растворе полимеров образуются ассоциаты, при этом освобождается связанная вода, которая переходит в равновесную водно-солевую фазу [18].

Эффективное извлечение лизина сополимером ВФ-МДМП, в отличие от ВФ-ВДМП, можно объяснить образованием более устойчивого комплекса за счет участия поляризованных $\mathrm{CO}$ групп звеньев МДМП при образовании Н-связей, диполь-дипольного и диполь-ионноого взаимодействия (рис. 1):

В работе изучена возможность применения сополимера $\mathrm{N}$-винил-формамида с 1-винил3,5-диметилпиразолом для совместного извлечения и селективного определения цистина, аспарагина и глутамина (табл. 3) при концентрации со-

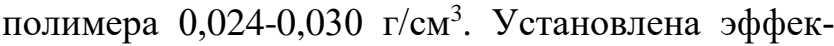
тивность ВФ-ВДМП в отношении изученных аналитов. Высокие экстракционные характеристики позволяют реализовать способ извлечения аминокислоты и моноамидов при однократной экстракции. Максимальная степень извлечения цистина, аспарагина и глутамина достигается при концентрации полимера $0,030 \Gamma / \mathrm{cm}^{3}$ и соотношении объ- емов водной и органической фаз 10:3. Отметим, что межфазное распределение глутамина и аспарагина характеризуется более высокими экстракционными показателями, чем для цистина.

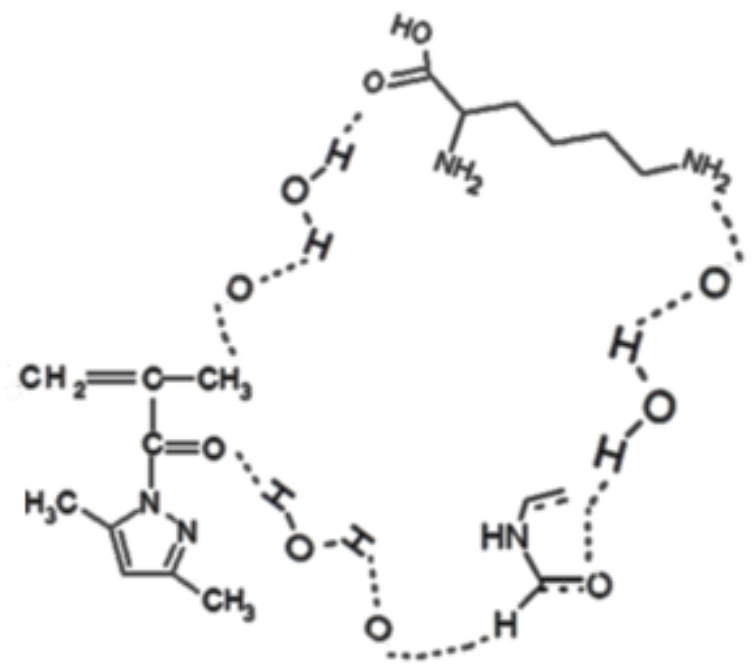

Рис. 1. Схема комплекса лизин - ВФ-МДМП Fig. 1. Scheme of the lysine - VF-MDMP

Таблица 3

Результаты межфазного распределения цистина и моноамидов аминокислот в системе ВФ-ВДМП

Table 3. Results of interphase distribution of cystine and monoamidesamino acids in the system VF-VDMP \begin{tabular}{|l|l|l}
\hline Концентрация ами- & Коэффициенты & Степень
\end{tabular}

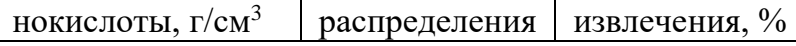

\begin{tabular}{|c|r|r|}
\hline \multicolumn{3}{|c|}{ Цистин } \\
\hline 0,010 & $23 \pm 2,2$ & 87,4 \\
\hline 0,020 & $25 \pm 2,3$ & 88,3 \\
\hline 0,025 & $41 \pm 3,5$ & 92,6 \\
\hline 0,030 & $43 \pm 3,2$ & 92,9 \\
\hline 0,035 & $35 \pm 2,8$ & 91,4 \\
\hline \multicolumn{3}{|c|}{ Аспарагин } \\
\hline 0,020 & $45 \pm 3,3$ & 93,2 \\
\hline 0,030 & $54 \pm 3,6$ & 94,2 \\
\hline 0,040 & $48 \pm 3,1$ & 93,6 \\
\hline 0,050 & $58 \pm 3,4$ & 94,6 \\
\hline 0,060 & $51 \pm 3,1$ & 93,9 \\
\hline \multicolumn{3}{|c|}{ Глутамин } \\
\hline 0,020 & $64 \pm 4,2$ & 95,0 \\
\hline 0,025 & $68 \pm 4,3$ & 95,4 \\
\hline 0,030 & $60 \pm 4,2$ & 94,8 \\
\hline 0,035 & $73 \pm 4,8$ & 95,7 \\
\hline 0,040 & $69 \pm 4,6$ & 95,4 \\
\hline
\end{tabular}

Полученные результаты позволяют предположить, что комплексообразование полимера с аминокислотой и моноамидами в водной среде происходит в результате формирования Н-связей между $>\mathrm{C}=\mathrm{O}$ группами звеньев цикла полимера и функциональными группами аналитов при уча- 
стии молекул воды. При этом комплексообразование возможно с участием «пиридинового» атома азота цикла и $\pi$-ненасыщенной электронной системы азольного (пиразольного) циклов в макроцепи сополимеров. Для всех изученных аналитов экстракция растворами сополимеров оказалась значительно эффективнее, чем традиционными органическими растворителями $[19,20]$.

Анализ концентрата осуществляли методом капиллярного электрофореза (рис. 2). Наличие высокоразрешенных пиков трех аналитов при совместном присутствии позволяет рекомендовать этот метод для раздельного определения в многокомпонентных смесях.

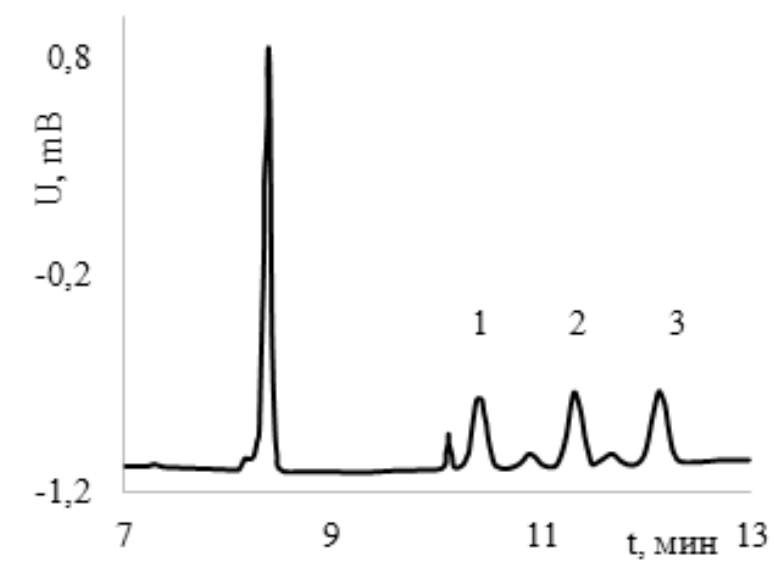

Рис. 2. Электрофореграммы глутамина (1), аспарагина (2) и цистина (3) при совместном присутствии

Fig. 2. Elektrophoregram of glutamine (1), asparagin (2) and cystine (3) at joint presence

\section{ЛИТЕРА Т У Р А}

1. Комов В.П., Шведова В.Н. Биохимия. М.: Дрофа. 2004. $638 \mathrm{c}$.

2. Алексюк М.П., Мельникова Е.И., Хрипушин В.В. Гомеостаз и питание: уч. пособие для студ. вузов. Воронеж: ВГТА. 2005. $172 \mathrm{c.}$

3. Машковский М.Д. Лекарственные средства. М.: 16-е изд. Новая Волна. 2012. 1216 с.

4. Справочник Видаль. Лекарственные препараты в России. Под ред. Е.А. Толмачевой. Видаль Рус. 2015. 1480 с.

5. Беликов В.Г. Современные синтетические и природные лекарственные средства. Краткий справочник. Пятигорск: ПГФА. 2000.335 с.

6. Шкинев В.М., Мокшина Н.Я., Хохлов В.Ю., Спиваков Б.Я. Экстракция биологически активных веществ в двухфазных водных системах на основе поли-Nвинилпирролидона. Докл. Академии наук. 2013. Т. 448. № 4. C. 427-429. DOI: 10.7868/S0869565213040166.

7. Коренман Я.И., Зыков А.В., Мокшина Н.Я., Быковский Д.В., Шаталов Г.В. Закономерности экс-тракции витаминов группы В синтетическими водорастворимыми полимерами. Журн. физич. химии. 2011. Т. 85. № 11. C. 2142-2146. DOI: 10.1134/S0036024411110185.

8. Доронин С.Ю., Чернова Р.К. Мицеллярная экстракция поверхностно-активными веществами - как способ концентрирования органических соединений. Бутлеров. сообщ. 2014. T. 40. № 10. C. 94-102.
При выборе условий электрофоретического определения аминокислоты и моноамидов найдены оптимальный состав буферного раствора, тип и концентрация мицеллообразователя, изучено влияние различных концентраций мицеллообразующего агента на разделяющую способность боратного буфера, установлены условия экстракционного извлечения аминокислот из водных сред (состав и рН экстрагента, время, температура). Общее время анализа составляет 30-40 мин.

\section{ВЫВОДЫ}

Экстракционные системы на основе водорастворимых сополимеров $\mathrm{N}$-винилформамида с 1-винил- (1-метакрилоил)-3,5-диметилпиразола могут применяться для извлечения из водных сред как отдельного представителя аминокислот, так и смесей аминокислоты и моноамидов кислот.

Экстракционные системы на основе сополимеров N-винилформамида с 1-метакрилоил-3,5диметилпиразолом, в отличие от сополимера с 1-винил-3,5-диметилпиразолом, позволяют при однократной экстракции лизина достичь практически количественной степени извлечения.

Установлена возможность методом капиллярного электрофореза раздельного определения аминокислоты на примере цистина при совместном присутствии с моноамидами кислот - аспарагином и глутамином.

\section{REFERENCES}

1. Komov V.P., Shvedova V.N. Biochemistry. M.: Bustard. 2004. 638 p. (in Russian).

2. Aleksyuk M.P., Melnikova E.I., Khripushin V.V. Homeostasis and nutrition: textbook for stud. higher educational. Voronezh: VSTA. 2005. 172 p. (in Russian).

3. Mashkovsky M.D. Medicines. M.: 16-th. ed. New Wave. 2012. 1216 p. (in Russian).

4. Reference Vidal. Drugs in Russia. Ed. by E.A. Tolmacheva. Vidal Rus. 2015. 1480 p. (in Russian).

5. Belikov V.G. Modern synthetic and natural drugs. Quick reference. Pyatigorsk: PGFA. 2000. 335 p. (in Russian).

6. Shkinev V.M., Mokshina N.Ya., Khokhlov V.Yu., Spivakov B.Ya. Extraction of biologically active substances in two-phase aqueous systems based on poly-Nvinylpyrrolidone. Dokl. Khim. 2013. V. 448. N 2. P. 49-51. DOI: 10.1134/S0012500813020055.

7. Korenman J.I., Zykov A.V., Mokshina N.Ya., Bykovskiy D.V., Shatalov G.V. Regularities of the extraction of b vitamins, synthetic water-soluble polymers. Zhurn. Fizich. Khim. 2011. V. 85. N 11. P. 2142-2146 (in Russian). DOI: 10.1134/S0036024411110185.

8. Doronin S.Y., Chernova R.K. Micellar extraction by surfactants as a way for concentrating organic compounds. Butlerov Soobshch.. 2014. V. 40. N 10. P. 94-102 (in Russian). DOI: jbc-02/14-40-12-94. 
9. Чернова Р.К., Доронин С.Ю. Определение органических аналитов в растворах ПАВ: ионные и мицеллярные эффекты. Саратов: Изд-во Сарат. ун-та. 2017. 200 с.

10. Мокшина Н.Я., Пахомова О.А., Шаталов Г.В., Лавлинская М.С. Экстракционно-электрофоретическое определение ванилина в водных растворах и энергетических напитках с применением полимеров на основе $\mathrm{N}$-винилформамида. Изв. вузов. Химия и хим. технология. 2017. Т. 60. Вып. 8. С. 13-19.

11. Кузнецов В.А., Быковский Д.В. Сорокин А.В., Лавлинская М.С. Влияние строения бокового азоль-ного заместителя на экстракционные способности сополимеров на основе N-виниламидов. Сорби. и хроматограф. проиессы. 2017. T. 17. № 5. C. 804-811. DOI: 10.17308/sorpchrom.2017.17/442.

12. Мокшина Н.Я., Быковский Д.В., Шаталов Г.В., Пахомова О.А. Общая методология межфазного распределения аминокислот и водорастворимых витаминов в разнохарактерных экстракционных системах. Конденсир. среды и межфаз. гранищьл. 2013. Т. 15. № 4. С. 423-427.

13. Карцова Л.А., Бессонова Е.А. Методы концентрирования в капиллярном электрофорезе. Журн. аналит. химии. 2009. Т. 64. № 4. С. 340-351.

14. Руденко А.О., Карцова Л.А., Сиарский С.И. Определение важнейших аминокислот в сложных объектах биологического происхождения методом обращенно-фазовой ВЭЖХ с получением фенилтиогидантоиновых производных. Сорби. и хроматограф. прочессы. 2010. Т. 10. Вып. 2. С. 223-230.

15. Чернова Р.К., Косырева И.В., Селифонова Е.И., Денисова Е.Н. Электрофоретическое разделение и цветометрическое определение некоторых $\alpha$-аминокислот. Изв. вузов. Химия и хим. технология. 2007. Т. 50. Вып. 9. С. 21-24.

16. Шаталов Г.В., Лавлинская М.С. Пахомова О.А., Мокшина Н.Я., Кузнецов В.А. Сополимеры $\mathrm{N}$-винилкапролактама с 1-винил- и 1-мета-крилоил-3,5-диметилпиразолом в качестве сорбентов незаменимых $\alpha$-аминокислот в жидко- и твердофазной экстракции. Журн. прикл. химии. 2016. Т. 89. Вып. 1. C. 112-118. DOI: $10.1134 / \mathrm{S} 1070427216010225$.

17. Мокшина Н.Я., Быковский Д.В., Шаталов Г.В., Пахомова О.А. Разделение бинарных смесей гистидина, пролина и метионина в экстракционных системах на основе водорастворимых полимеров винилового ряда. Журн. аналит. химии. 2016. Т. 71. № 2. C. 208-211. DOI: $10.1134 / \mathrm{S} 1061934816020106$

18. Мокшина Н.Я. Экстракция аминокислот и витаминов. Воронеж: Воронеж. гос. технол. акад. 2007. 246 с.

19. Мокшина Н.Я., Пахомова О.А., Нифталиев С.И. Экстракция аспарагина гидрофильными растворителями из водных растворов. Изв. вузов. Химия и хим. технология. 2006. Т. 49. Вып. 4. С. 8-11.

20. Мокшина Н.Я., Нифталиев С.И., Пахомова О.А. Экстракция некоторых алифатических аминокислот из водных растворов с применением смеси гидрофильных растворителей. Хим. технология. 2005. № 5. С. 44-46.
9. Chernova R.K., Doronin S.Y. Determination of organic analytes in surfactant solutions: ionic and mi-cellar effects. Saratov: Izd-vo Saratov. Un-ta. 2017. 200 p. (in Russian).

10. Mokshina N.Ya., Pakhomova O.A., Shatalov G.V., Lavlinsky M.S. Extraction-electrophoretic determination of vanillin in aqueous solutions and the energy drinks with the use of polymers on the basis of the N-vinylformamide. Izv. Vyssh. Uchebn. Zaved. Khim. Khim. Tekhnol. 2017. V. 60. N 8. P. 13-19 (in Russian). DOI: 10.6060/tcct.2017608.5577.

11. Kuznetsov V.A., Bykovskii D.V., Sorokin A.V., Lavlinskaya M.S. The effect of the side azole substitutes on extraction ability of the copolymers based on $\mathrm{N}$-vinylamides. Sorpts. Khromatogr. Prots. 2017. V. 17. N 5. P. 804-811 (in Russian).

12. Mokshina N.Ya., Bykovskiy D.V., Shatalov G.V., Pakhomova O.A. The general methodology of interphase distribution of amino acids and water-soluble vitamins in different character extraction systems. Kondens. Sredy Mezhfaz. Granitsy. 2013. V. 15. N 4. P. 423-427 (in Russian).

13. Kartsova L.A., Bessonova E.A. Preconcentration techniques in capillary electrophoresis. J. Analyt. Chem. 2009. V. 64. N 4. P. 326-337.

14. Rudenko A.O., Kartsova L.A., Siarsky S.I. Determination of the most important amino acids in complex objects of biological origin by the method of reversed-phase HPLC with obtaining phenylthiohydantoin derivatives. Sorpts. Khromatograp. Prots. 2010. V.10. N 2. P. 223-230 (in Russian).

15. Chernova R.K., Kosyreva I.V., Selifonova E.I., Denisova E.N. Electrophoretic separation and colorimetric determination of certain $\alpha$-amino acids. Izv. Vyssh. Uchebn. Zaved. Khim. Khim. Tekhnol. 2007. V. 50. N 9. P. 21-24 (in Russian).

16. Shatalov G.V., Lublinskaya M.S. Pakhomova O.A., Mokshina N.Ya., Kuznetsov V.A. Copolymers of N-vinylcaprolactam with 1-vinyl - and 1-metakilol-3,5-dimethylpyrazole as sorbents essential $\alpha$-amino acids in liquid- and solid-phase extraction. Zhurn. Prikl. Khim. 2016. V. 89. N 1. P. 112-118 (in Russian). DOI: 10.1134/S1070427216010225.

17. Mokshina N.Ya., Bykovskiy D.V., Shatalov G.V., Pakhomova O.A. Separation of binary mixtures of histidine, proline and methionine in the extraction systems based on water-soluble polymers of the vinyl series. J. Analyt. Chem. 2016. V. 71. N 2. P. 201-204. DOI: 10.1134/S1061934816020106.

18. Mokshina N.Ya. Extraction of amino acids and vitamins. Voronezh: VSTA. 2007. 246 p. (in Russian).

19. Mokshina N.Ya., Pakhomova O.A., Niftaliev S.I. Exstraction of asparagine from aqueous solutions with hidrophilic solvents. Izv. Vyssh. Uchebn. Zaved. Khim. Khim. Tekhnol. 2006. V. 49. N 4. P. 8-11 (in Russian).

20. Mokshina N.Ya., Niftaliev S.I., Pakhomova O.A. Extraction of some aliphatic amino acids from aqueous solutions with the use of a mixture of hydrophilic solvents. Khim. tekhnologiya. 2005. N 5. P. 44-46 (in Russian).

Поступила в редакиию 12.02.2018

Принята к опубликованию 03.12.2018

Received 12.02.2018

Accepted 03.12.2018 